\title{
Detecting alliance ruptures: the effects of the therapist's experience, attachment, empathy and countertransference management skills
}

\author{
Corinne Talbot, ${ }^{1}$ Rose Ostiguy-Pion, ${ }^{1}$ Esther Painchaud, ${ }^{1}$ Claudelle Lafrance, ${ }^{2}$ Jean Descôteaux ${ }^{1}$ \\ ${ }^{1}$ Departement of Psychology, University of Sherbrooke; ${ }^{2}$ Departement of Psychology, University of Québec à Trois-Rivières, QC, \\ Canada
}

\begin{abstract}
Accurate alliance rupture detection is a prerequisite to any successful repair process. Despite its importance, however, rupture detection remains a struggle for most therapists. Supporting the existence of a therapist effect on therapy outcomes, rupture detection skills may rely on certain therapists' personal characteristics. The aim of this study was to verify whether alliance rupture detection performance is related to therapists' personal characteristics. One hundred and eight undergraduates, trainees and mental health professionals participated in an experimental task assessing their alliance rupture detection ability. Participants also completed attachment, empathy and countertransference management self-reported measures. Participants with clinical experience (trainees and professionals) reported more alliance ruptures, accurate or not, than those with no clinical experience (undergraduates). Trainees reported more accurate ruptures and less inaccurate ones than the two other groups. Attachment anxiety was positively associated with accurate ruptures detection for undergraduates, while this association proved negative for trainees and therapists. Perspective-taking, a cognitive dimension of empathy, was negatively associated with accurate rupture detection, whereas personal distress, an affective dimension of empathy, was negatively associated with accurate ruptures detection for trainees, and positively associated for undergraduates. Self-insight, a component of countertransference management, revealed a negative association with accurate rupture detection for trainees. These find-

Correspondence: Corinne Talbot, Departement of Psychology, University of Sherbrooke, 2500 Boulevard de l'Université, Sherbrooke, Québec, J1K 2R1, Canada.

Tel.: 1.819.821.8000 - Fax: 819.821.7925.

E-mail: corinne.talbot@usherbrooke.ca ings suggest that therapists vary as to their rupture detection ability and that this ability is related to certain personal characteristics. They also highlight the importance of specific training and clinical supervision for both trainees and experienced therapists in order to improve their detection ability.
\end{abstract}

Citation: Talbot, C., Ostiguy-Pion, R., Painchaud, E., Lafrance, C., \& Descôteaux, J. (2019). Detecting alliance ruptures: the effects of the therapist's experience, attachment, empathy and countertransference management skills. Research in Psychotherapy: Psychopathology, Process and Outcome, 22(1), 19-28. doi: 10.4081/ripppo.2019.325

Contributions: the authors contributed equally.

Conflict of interest: the authors declare no potential conflict of interest.

Acknowledgements: the authors would like to thank Thomas Aubin and Tasha Keri for revising their manuscript.

Funding: none.

Dedication: the article is dedicated to Professor Jeremy Safran, whose work inspired us and made us want to become better therapists.

Received for publication: 30 July 2018.

Revision received: 16 January 2019.

Accepted for publication: 3 February 2019.

This work is licensed under a Creative Commons Attribution NonCommercial 4.0 License (CC BY-NC 4.0).

CCopyright C. Talbot et al., 2019

Licensee PAGEPress, Italy

Research in Psychotherapy:

Psychopathology, Process and Outcome 2019; 22:19-28

doi:10.4081/ripppo.2019.325
Key words: Alliance ruptures; Detection; Treatment outcome; Therapist characteristics; Therapy relationship.

\section{Introduction}

Decades of research has demonstrated the important effect of therapeutic alliance and therapist' characteristics on therapy outcome (Ackerman \& Hilsenroth, 2001, 2003; Horvath, Del Re, Flückiger, \& Symonds, 2011; Wampold, 2015). In line with these findings, recent empirical results suggest that the therapists' capacity to accurately and efficiently detect alliance ruptures is essential to engage in rupture reparation and that this process, when successful, tends to improve both alliance and therapeutic outcome (Chen, Atzil-Slonim, Bar-Kalifa, HassonOhayon, \& Refaeli, 2018; Marmarosh \& Kivlighan, 2012). It appears, however, that therapists often fail to recognize alliance ruptures as they occur within sessions and that some are better at recognition than others (EubanksCarter, Muran, \& Safran, 2010; Johnson et al., 1995; Lecomte, Savard, Drouin, \& Guillon, 2004; Safran \& Muran, 2000). Knowledge about the characteristics that distinguish those who are proficient at alliance rupture detection from those who are not (Chen et al., 2018) could contribute to the global outcome improvement effort. The 
aim of this study is to verify whether some therapists' personal characteristics are associated with their alliance rupture detection performance.

An alliance rupture can be defined as a tension or breakdown in the collaborative relationship between the patient and the therapist (Safran, Crocker, McMain, \& Murray, 1990; Safran \& Muran, 2000), as well as a difficulty to establish a therapeutic bond early in the process (Samstag, Muran, \& Safran, 2004). Based on the patient's behavior, Safran and Muran (2000) identified two types of alliance ruptures. On the one hand, a confrontation rupture refers to any hostile reaction where the patient expresses his or her anger, resentment or dissatisfaction towards the therapist or technical aspects of the treatment in a blaming or demanding manner. On the other hand, a withdrawal rupture occurs when the patient deals with a trigger in the relationship with the therapist by remaining silent, offering minimal answers to questions, changing subject or being excessively compliant to the therapist's recommendations.

Over the last two decades, Safran and colleagues' pioneer work have allowed a better understanding of the rupture-repair processes. For instance, alliance ruptures, when adequately addressed, are now known to be beneficial to therapeutic change, as they offer the opportunity to explore the patient's interpersonal patterns in the hereand-now (Safran \& Muran, 1996, 2000; Safran, Muran, Samstag, \& Stevens, 2002; Stevens, Muran, Safran, Gorman, \& Winston, 2007). In the Latin American context, moments of conflicts engendering strong emotions for the client, perceived as breaches in the alliance, also proved central to therapeutic change when acknowledged and repaired (Krause et al., 2007; Krause, Altimir, \& Horvath, 2011). Conversely, unattended ruptures represent missed opportunities to engage in a negotiation and resolution process (Regan \& Hill, 1992; Rhodes, Hill, Thompson, \& Elliott, 1994) and as such, have the potential to harm the relationship, decrease the likelihood of therapeutic gains, increase stagnation and promote early patient dropout (Mellado et al., 2017; Muran et al., 2009; Safran, Muran, Samstag, \& Winston, 2005; Safran, Muran, \& EubanksCarter, 2011). As recent empirical papers pointed out, whether ruptures prove beneficial or not depends on the therapist's ability to manage them and also, most importantly, on his or her ability to detect them (Chen et al., 2018; Marmarosh \& Kivlighan, 2012).

Several ways of operationalizing rupture detection have been proposed over time, based on various conceptualizations of ruptures (Coutinho, Ribeiro, Sousa, \& Safran, 2014). For instance, some consider ruptures as series of events occurring within a single therapy session (Colli, Gentile, Condino, \& Lingiardi, 2017; Colli \& Lingiardi, 2009; Safran, Muran, \& Samstag, 1994), while others consider them as alliance ratings fluctuations from one session to another (Stiles et al., 2004; Strauss et al., 2006). Operationalizations also vary as to their method- ology. Some are based on self-reports from patients and therapists (WAI; Horvath \& Greenberg, 1989; CALPAS; Marmar \& Gaston, 1988), while others rely on observers or judges who apply predefined coding methods on video (3RS; Eubanks, Muran, \& Safran, 2015) or transcript data (CIS-R; Colli et al., 2017; CIS; Colli \& Lingiardi, 2009). Eubanks et al. $(2010,2018)$ claimed that self-reported questionnaires are less effective than observation-based methods, which allow the detection of more ruptures, including those unsuspected and uncomfortable to report by both individuals. Among the observer-based methods, the most frequently used, according to Eubanks, Muran, and Safran (2018), is the Rupture Resolution Rating System (3RS; Eubanks et al., 2015). This method lists specific behavioral markers facilitating the identification of the types of ruptures occurring over the course of sessions.

Based on multiple findings suggesting the presence of a therapist effect on alliance's quality, therapist-variance according to rupture detection has recently become a subject of interest to many authors (Chen et al., 2018; Eubanks-Carter, Muran, \& Safran, 2015; Safran \& Kraus, 2014). The current theoretical knowledge suggests that clinical experience, attachment style and countertransference (CT) management ability could be involved in therapists' ability to detect ruptures.

The difficulty to deal with alliance ruptures (Lecomte et al., 2004) and to recognize their presence (Hill, 2010) has been found to persist among experienced therapists. Chen and colleagues (2018) suggested that experienced therapists might be more effective at detecting ruptures as they occur, whereas trainees tend to base their judgments on their supervisor's perceptions of tensions in the alliance. In line with Coutinho and colleague's suggestion (2014), the authors (Chen et al., 2018) also recommended to keep exploring the implication of clinical experience in regard to the ability to detect ruptures.

The therapist's attachment style is already known to play a significant role as to the quality of the therapeutic alliance (Black, Hardy, Turpin, \& Parry, 2005; Degnan, Seymour-Hyde, Harris, \& Berry, 2016; Eames \& Roth, 2000; Rubino, Barker, Roth, \& Fearon, 2000; Sauer, Lopez, \& Gormley, 2003) and some studies suggest that it might also be involved in the definition of rupture detection ability. On the one hand, characteristics observed in individuals with a secure attachment, such as emotional regulation, conflict tolerance, accurate perception of others' intentions and forgiveness (Mikulincer \& Shaver, 2016), have been suggested as facilitating the detection of alliance ruptures (Marmarosh et al., 2015). On the other hand, attachment insecurities could influence awareness of rupture occurrences, as anxiously attached therapists tend to report more ruptures, difficulties during therapy sessions and weaker alliances than avoidant therapists (Black et al., 2005; Dinger, Strack, Sachsse, \& Schauenberg, 2009; Marmarosh et al., 2014; Marmarosh et al., 2015; Sauer et al., 2003). These studies, however, did not 
determine whether the therapists' attachment insecurities contributed to the creation of actual alliance ruptures with their patients or whether they mainly generated perceptual biases as to the number of ruptures detected. As of yet, no study appears to have addressed the eventuality of perceptual biases on the part of therapists.

When therapists are confronted to alliance ruptures, they tend to experience emotional reactions also encountered in countertransference (Coutinho, Ribeiro, Hill, \& Safran, 2011). The fact that some therapists are better than others at countertransference management is well documented (Van Wagoner, Gelso, Hayes, \& Diemer, 1991) and some personal characteristics, such as awareness of one's affective reactions and empathic dispositions, have been defined as central to this ability. Interestingly, some authors have suggested that therapists' awareness of their own emotional reactions allow better detection of ruptures as it leads them to be more attuned to signs of negative shifts taking place in the relationship in the here-and-now (EubanksCarter et al., 2015; Safran, Muran, Stevens, \& Rothman, 2007; Safran \& Kraus, 2014). Conversely, low empathy appears likely to lead therapists to ignore signs of alliance ruptures in the therapeutic process as well as to negate their own contribution (Ackerman \& Hilsenroth, 2001).

\section{Objectives and hypotheses}

The aim of this study is to explore the association between therapists' specific personal characteristics and their alliance rupture detection performance while taking into account clinical experience levels. Building on parameters frequently used to define the performance of diagnostic tools in biomedical applications (Tabachnick \& Fidell, 2007; Zweig \& Campbell, 1993), the ability to detect ruptures is approached from two perspectives: i) sensitivity (true positives, i.e. number of accurate ruptures reported), and ii) 1-specificity (false positives, i.e. number of inaccurate ruptures reported). The first hypothesis states that clinical experience level is positively associated to detection performance, characterized by increased reports of accurate ruptures (sensitivity) and fewer reports of inaccurate ruptures (specificity). The second hypothesis states that attachment insecurities are negatively associated with detection performance (fewer reports of accurate ruptures and increased reports of inaccurate ones), whereas empathy and countertransference management ability are positively associated with detection performance as characterized here-above.

\section{Materials and Methods}

\section{Sample}

Following the approval of the project by the Research Ethics Board (Humanities and Social Sciences, University of Sherbrooke, certification number 2017-1650), the sample consisted of 108 undergraduate, graduate and post- graduate students in psychology, psychoeducation, social work and vocational counseling from three Canadian universities, as well as currently working clinical psychologists and other mental health professionals (social workers, psychoeducators, guiding counselors, occupational therapists). Participants were recruited from the provincial psychologists' certification board (Quebec Board of Psychologists) mailing list, student mailing lists, and via publicity in universities and on social networks.

\section{Procedure}

Participants were invited to take part in an individual interview of approximately 90 minutes. The course of the study and its implications were explained in order to obtain free and informed consent. Following this, the experimental task and the completion of self-reported measures on a secured online survey platform were completed.

\section{Experimentation}

A brief and informational presentation about alliance ruptures and their detection, as well as instructions related to the task, were provided by the researcher before exposure to the stimuli in order to ensure information uniformity and to limit biases related to differences inherent to field of study or practice. The stimuli consisted of three video excerpts, each ranging from 9 to 12 minutes, starring a therapist and three different patients interacting during psychotherapy sessions (details below). Participants were asked to pause playback when they detected an alliance rupture. They were instructed to specify the patient's sentence marking the beginning of the rupture as well as the behavioral clues they used to draw their conclusion. A printed copy of transcripts of each video excerpt had previously been given to the participants, allowing them to pinpoint the exact sentence considered as the beginning of the rupture. Finally, in order to facilitate analysis, the verbal answers given by the participants were recorded on a digital audio device

\section{Instruments}

\section{Sociodemographic variables}

Age, gender, clinical experience and field of study or occupation were collected for descriptive purposes.

\section{Video excerpts}

Three excerpts were selected from a Canadian (Quebec) adaptation of In treatment, a television series depicting realistic therapy sessions and alliance ruptures. In order to properly use the Rupture Resolution Rating System (3RS) elaborated by Eubanks, Muran, and Safran (2015), four judges trained from the available documentation on Safran's laboratory website as well as through the analysis of video excerpts until a good inter-judge agreement was reached. Afterwards, the judges used the 
3RS to individually analyze the three excerpts in order to determine the precise timing at which the ruptures began according to the first indicative behavioral manifestation. The three excerpts respectively included seven, two and eleven ruptures. The average agreement percentage between the judges was $72 \%$. Disagreements were discussed to reach consensus and an answer key listing a total of 20 ruptures was produced.

\section{Attachment}

In order to assess the participants' attachment insecurities, a French version (Lafontaine \& Lussier, 2003) of the 12-item inventory of the Experience in Close Relationships (ECR; Wei, Russel, Mallinckrodt, \& Vogel, 2007) was used. The instrument, whose items are answered on a 7-point Likert scale, is divided into two dimensions, namely anxiety and avoidance. The dimensions present good to excellent internal consistency, $\alpha$ ranging from 0.77 to 0.88 . Validity is well established, with recent studies confirming the validity indices from the initial validation stage (Wei et al., 2007).

\section{Empathy}

In order to measure empathy, the French version (Lussier, 1996) of the Interpersonal Reactivity Index (IRI; Davis, 1980), was used. This version contains 28 items to be answered on a 7-point Likert scale and grouped into four dimensions, namely fantasy, perspective-taking, empathic concern and personal distress. The dimensions present mostly acceptable internal consistency, $\alpha$ ranging from 0.55 to 0.77 , and a good convergent validity (Gilet, Mella, Studer, Grühn, \& Labouvie-Vief, 2013).

\section{Countertransference management}

In order to measure characteristics involved in countertransference management, a French translation of the Countertransference Factors Inventory (CFI; Van Wagoner et al., 1991) was used. The questionnaire contains 51 items to be answered on a 7-point Likert scale, documenting five dimensions: self-insight, self-integration, empathy, anxiety management, and conceptualization skills. The dimensions present excellent internal consistency, $\alpha$ ranging from 0.88 to 0.92 . Content validity is well established (Van Wagoner et al., 1991). The questionnaire was created to be completed by an observer but can also be self-reported (Rosenberger \& Hayes, 2002). The second option was chosen for the needs of the present study.

\section{Results}

\section{Preliminary analyses}

Of the 108 participants recruited for this study, 86 were female (80.4\%) and 21 male (19.6\%), and ranged in age between 19 - and 69 years of age $(M=30.21, S D=11.10)$.
Most participants were students (66.7\%), while others were professionals $(31.5 \%)$ or pursuing other occupations $(1.9 \%)$. A large part of the sample was psychology-related, as $18.6 \%$ of participants were psychotherapists, $23.3 \%$ were trainees and $33.3 \%$ were undergraduates, while the remaining $24.8 \%$ were students or professionals involved in psychosocial intervention (social work, psychoeducation, vocational guidance).

In order to calculate the number of accurate and inaccurate rupture reports, researchers listened to the recording of each participant and compiled all ruptures reported. Their answers were then rated based on the answer key, adding a score of 1 on the number of accurate ruptures variable when participants detected the right timing of a rupture, leading to the establishment a final score out of 20 , and a score of 1 on the number of inaccurate ruptures variable when the timing did not correspond to any of those included in the key list.

The clinical experience variable was turned into a categorical variable with three possible values: i) no clinical experience $(n=44)$, ii) 22 months of practice or less $(n=33)$ and iii) more than 22 months of practice $(n=31)$. This procedure generated three groups of relatively similar sizes. The first group was only composed of undergraduates $(100.0 \%)$, the second group was mostly composed of trainees $(81.8 \%)$ and the third group was mostly composed of professionals $(84.9 \%)$. Mean clinical experience for the trainees' and professionals' groups were respectively $10.6(S D=1.1)$ and $157.3(S D=20.3)$ months.

In order to proceed with the analyses, some variables had to be transformed: square root transformation was used for the anxiety dimension and a logarithmic transformation was used for the avoidance dimension of attachment as well as the number of accurate and inaccurate reports. Table 1 reports means and standard deviations for each group on the study variables. As described in more details below, differences were observed on the rupture detection performance variables. Furthermore, whereas groups were no different on the attachment variables and on three out of four of the empathy dimensions (Davis, 1983), they showed significant differences on the remaining variables. The majority of these highlighted differences were found between the professionals and the two other groups, who did not differ from each other.

\section{Effect of clinical experience on rupture detection performance}

In order to assess the effect of clinical experience on rupture detection performance (hypothesis 1), ANOVAs were performed on the number of accurate and inaccurate ruptures reported by each group. Differences on both were significant, respectively $F(2,105)=5.959, \mathrm{P}<.004$ and $F(2,105)=4.433, \mathrm{P}<.014$. Results of REGWQ post-hoc comparisons showed that trainees reported significantly more accurate $(M=.78, S D=.26)$ and inaccurate $(M=.88$, 
$S D=.20)$ ruptures than undergraduates $(M=.60, S D=.23$; $M=.78, S D=.21$ ). They also revealed that mental health professionals identified a significantly higher number of accurate $(M=.74, S D=.21)$ and inaccurate $(M=.92$, $S D=.22$ ) ruptures than undergraduates. No significant differences were found between trainees and professionals regarding detection performance.

\section{Effect of personal characteristics on rupture detection performance}

In order to verify whether the therapists' attachment insecurities were negatively associated with their detection performance, and whether their empathy and CT management ability were positively related to their detection performance (hypothesis 2), a series of eleven hierarchical multiple linear regressions were performed on the amount of accurate and inaccurate ruptures reported. As presented in Table 2, clinical experience remained the variable explaining the highest amount of variance, respectively $10.2 \%$ and $7.8 \%$. Only one significant main effect was listed, that of perspective taking on the number of accurate ruptures detected $(\beta=-.189)$. Two interaction effects on the number of accurate ruptures detected proved also significant, the interaction of experience with attachment anxiety and self-insight respectively adding $7.5 \%$ and $5.9 \%$ to the variance explained. Finally, the interactions of experience with personal distress added a marginal contribution of $4.4 \%$.

Table 3 lists the simple slopes associated with the significant and marginally significant interaction effects. The association between attachment anxiety and the number of ruptures accurately detected is positively stronger for the undergraduates than it is for the other groups, while the association between self-insight and the number of accurate ruptures is negatively stronger for the trainees as compared to the other groups. Finally, personal distress exerts a more positive effect on the number of accurate ruptures reported for undergraduates than it does for the trainees.

\section{Discussion}

The results of the current study tend to confirm the ideas put forth by various authors regarding the existence of a therapist effect on rupture detection ability (Chen et al., 2018; Eubanks-Carter et al., 2015; Safran \& Kraus, 2014). Indeed, clinical experience is associated with increased reports of both accurate and inaccurate ruptures in comparison to no experience, thus partially confirming the first hypothesis. Although the differences were not statistically significant, trainees showed the best detection performance as they reported less inaccurate ruptures and more accurate ones than professionals. In addition, professionals reported significantly more inaccurate ruptures than undergraduates, thus partially offsetting their favorable results as to detection specificity. These findings are in line with therapists reported persistent struggle to detect and manage alliance ruptures (Lecomte et al., 2004; Safran \& Muran, 2000).

Our findings suggest that therapists' sensitivity towards the deterioration of the quality of the therapeutic relationship increases with experience but lacks speci-

Table 1. Means and standard deviations on study variables per group.

\begin{tabular}{|c|c|c|c|}
\hline Groups & & & \\
\hline Predictors & Undergraduates & Trainees & Professionals \\
\hline \multicolumn{4}{|l|}{ Rupture detection performance } \\
\hline Accurate ruptures & $.60(.23)^{\mathrm{a}}$ & $.78(.26)^{\mathrm{b}}$ & $.74(.21)^{\mathrm{b}}$ \\
\hline Inaccurate ruptures & $.78(.21)^{\mathrm{a}}$ & $.88(.20)^{\mathrm{a}, \mathrm{b}}$ & $.92(.22)^{\mathrm{b}}$ \\
\hline Attachment style & & $1.84(.35)$ & $1.71(.37)$ \\
\hline Attachment anxiety & $1.69(.37)$ & & \\
\hline Attachment avoidance & $.28(.19)$ & $.26(.18)$ & $.31(.15)$ \\
\hline \multicolumn{4}{|l|}{ Empathy } \\
\hline Fantasy & $2.94(.65)^{\mathrm{a}}$ & $2.93(.67)^{\mathrm{a}}$ & $2.47(.76)^{\mathrm{b}}$ \\
\hline Empathic concern & $3.16(.54)$ & $3.15(.59)$ & $2.93(.66)$ \\
\hline Perspective-taking & $3.19(.44)$ & $3.19(.44)$ & $2.98(.67)$ \\
\hline Personal distress & $1.35(.76)$ & $1.35(.76)$ & $1.30(.85)$ \\
\hline Countertransference management ability & & $3.91(.55)^{\mathrm{a}}$ & \\
\hline Anxiety management & $3.91(.55)^{\mathrm{a}}$ & $3.93(.38)^{\mathrm{a}}$ & $4.28(.44)^{\mathrm{b}}$ \\
\hline Empathy & $4.01(.30)^{\mathrm{a}}$ & $4.05(.28)^{\mathrm{a}}$ & $4.24(.43)^{\mathrm{b}}$ \\
\hline Conceptualization skills & $3.61(.43)^{\mathrm{a}}$ & $3.83(.44)^{\mathrm{a}, \mathrm{b}}$ & $4.05(.48)^{\mathrm{b}}$ \\
\hline Self-insight & $3.74(.53)^{\mathrm{a}}$ & $3.80(.33)^{\mathrm{a}}$ & $4.05(.41)^{\mathrm{b}}$ \\
\hline Self-integration & $3.83(.46)^{\mathrm{a}}$ & $3.85(.31)^{\mathrm{a}}$ & $4.10(.46)^{\mathrm{b}}$ \\
\hline$n$ & 44 & 33 & 31 \\
\hline
\end{tabular}


Table 2. Hierarchical multiple regressions predicting number of accurate and inaccurate ruptures reported from clinical experience, attachment style, empathy, countertransference management ability $(\mathrm{N}=108)$.

Rupture detection performance

\begin{tabular}{|c|c|c|c|c|c|c|c|c|}
\hline \multirow{2}{*}{$\overline{\text { Step }}$} & \multirow[b]{2}{*}{ Predictor } & \multirow[b]{2}{*}{ Effects } & \multicolumn{3}{|c|}{ Accurate ruptures } & \multicolumn{3}{|c|}{ Inaccurate ruptures } \\
\hline & & & $\boldsymbol{\beta}$ & $\Delta R^{2} / R^{2}$ & $\Delta F / F_{\text {total }}$ & $\beta$ & $\Delta R^{2} / R^{2}$ & $\Delta F / F_{\text {total }}$ \\
\hline \multirow[t]{3}{*}{1} & Clinical experience & & - & .102 & $5.959^{* *}$ & - & .078 & $4.433^{*}$ \\
\hline & & Undergraduates $v s$ Trainees (CE1) & $.326^{* *}$ & - & - & $.211^{*}$ & - & - \\
\hline & & Undergraduates $v s$ Professionals (CE2) & $.257^{*}$ & - & - & $.292^{* *}$ & - & - \\
\hline 2 & Attachment anxiety & Main effect & .072 & .005 & .587 & .084 & .007 & .772 \\
\hline \multirow[t]{3}{*}{3} & & Interaction & - & .075 & $4.668^{*}$ & - & .032 & 1.819 \\
\hline & & x CE1 & $-.240^{*}$ & - & - & .157 & - & - \\
\hline & & $\mathrm{x}$ CE2 & $.341^{* *}$ & - & - & -.096 & - & - \\
\hline Total & & All effects & - & .182 & $4.534^{* *}$ & - & .116 & $2.682^{*}$ \\
\hline 2 & Attachment avoidance & Main effect & -.056 & .003 & .358 & -.028 & .001 & .086 \\
\hline \multirow[t]{3}{*}{3} & & Interaction & - & .022 & 1.314 & - & .005 & .265 \\
\hline & & x CE1 & -.071 & - & - & -.040 & - & - \\
\hline & & $\mathrm{x}$ CE2 & -.179 & - & - & .057 & - & - \\
\hline Total & & All effects & - & .127 & $2.981^{*}$ & - & .083 & 1.856 \\
\hline 2 & Fantasy & Main effect & .025 & .001 & .064 & .143 & .019 & 2.149 \\
\hline \multirow[t]{3}{*}{3} & & Interaction & - & .008 & .445 & - & .003 & .169 \\
\hline & & x CE1 & .070 & - & - & -.040 & - & - \\
\hline & & x CE2 & .130 & - & - & -.081 & - & - \\
\hline Total & & All effects & - & .110 & $2.528^{*}$ & - & .100 & $2.255^{* * *}$ \\
\hline 2 & Empathic concern & Main effect & .064 & .004 & .460 & .034 & .001 & .126 \\
\hline \multirow[t]{3}{*}{3} & & Interaction & - & .001 & .055 & - & .012 & .698 \\
\hline & & x CE1 & -.029 & - & - & .053 & - & - \\
\hline & & $\mathrm{x}$ CE2 & .014 & - & - & -.105 & - & - \\
\hline Total & & All effects & - & .107 & $2.440^{*}$ & - & .091 & $2.053^{* * *}$ \\
\hline 2 & Perspective taking & Main effect & $-.189^{*}$ & .035 & $4.209^{*}$ & .111 & .012 & 1.373 \\
\hline \multirow[t]{3}{*}{3} & & Interaction & - & .011 & .688 & - & .018 & 1.037 \\
\hline & & x CE1 & .013 & - & - & -.116 & - & - \\
\hline & & $x$ CE2 & .154 & - & - & -.219 & - & - \\
\hline Total & & All effects & - & .148 & $3.554^{* *}$ & - & .108 & $2.471^{*}$ \\
\hline 2 & Personal distress & Main effect & .126 & .015 & 1.820 & -.026 & .001 & .073 \\
\hline \multirow[t]{3}{*}{3} & & Interaction & & .044 & $2.692^{* * *}$ & & .002 & .121 \\
\hline & & x CE1 & $-.262^{*}$ & - & - & -.046 & - & - \\
\hline & & $x$ CE2 & -.102 & - & - & .017 & - & - \\
\hline Total & & All effects & - & .162 & $3.933^{* *}$ & - & .081 & 1.791 \\
\hline 2 & Anxiety management & Main effect & -.101 & .009 & 1.073 & .136 & .017 & 1.898 \\
\hline \multirow[t]{3}{*}{3} & & Interaction & - & .012 & .686 & - & .004 & .217 \\
\hline & & AM x CE1 & .060 & - & - & .013 & - & - \\
\hline & & AM x CE2 & .143 & - & - & .083 & - & - \\
\hline Total & & All effects & - & .123 & $2.858^{*}$ & - & .098 & $2.222^{* * *}$ \\
\hline 2 & Empathy & Main effect & -.032 & .001 & .107 & .108 & .011 & 1.225 \\
\hline \multirow[t]{3}{*}{3} & & Interaction & - & .007 & .401 & - & .002 & .116 \\
\hline & & EMP x CE1 & -.091 & - & - & .005 & - & - \\
\hline & & EMP x CE2 & .010 & - & - & -.062 & - & - \\
\hline Total & & All effects & - & .110 & $2.517^{*}$ & - & .091 & $2.034^{* * *}$ \\
\hline 2 & Conceptualization skills & Main effect & -.022 & .000 & .048 & .130 & .014 & 1.646 \\
\hline \multirow[t]{3}{*}{3} & & Interaction & - & .007 & .373 & - & .002 & .139 \\
\hline & & CS x CE1 & .107 & - & - & .066 & - & - \\
\hline & & CS x CE2 & .040 & - & - & .031 & - & - \\
\hline Total & & All effects & - & .109 & $2.492^{*}$ & - & .095 & $2.134^{* * *}$ \\
\hline
\end{tabular}


ficity. We suspect that doing psychotherapy may lead to a redefinition of the cost/benefit ratio associated with rupture detection. In this sense, therapists may learn through experience that the cost of an undetected rupture may potentially surpass the cost of a false positive, as they may lead to an abrupt downfall of the patient's trust, increasing the risk of premature therapy termination and preventing any possibility of resolution. Furthermore, raising the matter of a rupture while there is none could prove less harmful for the therapeutic process, even perhaps positive given the increased attention to interpersonal processes (Chen et al., 2018), given that both parties are still there to discuss the issue. If this were the case, false positive rupture reporting would not substantially reduce as experience increases.

The second hypothesis stating that attachment insecurity is negatively associated with rupture detection performance, whereas empathy and countertransference management ability is positively related to this ability, was partially confirmed. Indeed, of both attachment dimensions, only anxiety showed an effect on accurate ruptures detection, which differed based on level of clinical experience. In fact, attachment anxiety revealed a strong positive effect on accurate ruptures reported by the group with no clinical experience and a comparatively negative effect on number of accurate ruptures reported by those with clinical experience. The negative effect of attachment anxiety on alliance ruptures detection could be explained by the hypervigilance anxiously attached therapists encounter in their attempt to avoid inducing negative reactions in others and feel rejected (Simpson, Rholes, \& Phillips, 1996). As they tend to perceive ruptures as patients' intentions to leave (Safran et al., 1994), their fear of rejection could lead them, on the one hand, to constantly look out for tensions in the therapeutic relationship, thus being particularly attentive to the slightest behavioral sign that may indicate the presence of ruptures. On the other hand, they might think that ruptures ought not to be so omnipresent than what they feel, thus casting doubts on the accuracy of their perception of ruptures. These doubts could in turn be maintained, indeed reinforced, by a lack of verification with the patient for fear of triggering an eventual negative reaction. The negative effect of attachment anxiety on rupture detection performance appears also consistent with the findings of numerous studies which highlight the negative effects of therapists' attachment anxiety on their assessment of the quality of the therapeutic alliances (Black et al., 2005;

Table 2. Continued from previous page.

\begin{tabular}{|c|c|c|c|c|c|c|c|c|}
\hline \multirow[b]{3}{*}{ Step } & \multirow[b]{3}{*}{ Predictor } & \multirow[b]{3}{*}{ Effects } & \multicolumn{6}{|c|}{ Rupture detection performance } \\
\hline & & & \multicolumn{3}{|c|}{ Accurate ruptures } & \multicolumn{3}{|c|}{ Inaccurate ruptures } \\
\hline & & & $\beta$ & $\Delta R^{2} / R^{2}$ & $\Delta F / F_{\text {total }}$ & $\beta$ & $\Delta R^{2} / R^{2}$ & $\Delta F / F_{\text {total }}$ \\
\hline 2 & Self-insight & Main effect & -.028 & .001 & .086 & .027 & .001 & .074 \\
\hline 3 & & $\begin{array}{l}\text { Interaction } \\
\text { S-INS x CE1 } \\
\text { S-INS x CE2 }\end{array}$ & $\begin{array}{c}- \\
-.248^{*} \\
.066\end{array}$ & $\begin{array}{c}.059 \\
- \\
- \\
\end{array}$ & $\begin{array}{c}3.595^{*} \\
- \\
- \\
\end{array}$ & $\begin{array}{c}- \\
-.096 \\
.055 \\
\end{array}$ & $\begin{array}{c}.011 \\
- \\
- \\
\end{array}$ & $\begin{array}{c}.637 \\
- \\
- \\
\end{array}$ \\
\hline Total & & All effects & - & .162 & $3.937^{* *}$ & - & .090 & $2.015^{* * *}$ \\
\hline 2 & Self-integration & Main effect & .043 & .002 & .200 & .154 & .022 & 2.538 \\
\hline 3 & & $\begin{array}{l}\text { Interaction } \\
\text { S-INT x CE1 } \\
\text { S-INT x CE2 }\end{array}$ & $\begin{array}{c}- \\
.077 \\
.103\end{array}$ & $\begin{array}{c}.008 \\
- \\
-\end{array}$ & $\begin{array}{c}.432 \\
- \\
-\end{array}$ & $\begin{array}{c}- \\
-.024 \\
.073\end{array}$ & $\begin{array}{c}.004 \\
- \\
-\end{array}$ & $\begin{array}{c}.248 \\
- \\
-\end{array}$ \\
\hline Total & & All effects & - & .111 & $2.552^{*}$ & - & .104 & $2.373^{*}$ \\
\hline
\end{tabular}

Bloc 1 is the same for all regressions performed on a given dependent variable. $d f=2,105$ for bloc $1, d f=1,104$ for bloc $2, d f=2,102$ for bloc 3 and $d f=5,102$ for total. ${ }^{*} \mathrm{P}<.05$; ${ }^{* * *} \mathrm{P}<.01 ;{ }^{* * *} .05<\mathrm{P}<.10 ; \mathrm{CE}$, Clinical Experience.

Table 3. Simple slope estimates $(\beta)$ for significant interactions on number of accurate ruptures reported.

\begin{tabular}{lccc}
\hline Predictors & Undergraduates & Trainees & Professionals \\
\hline Attachment anxiety & $.385^{* *_{\mathrm{a}}}$ & $-.059^{\mathrm{b}}$ & $-.253^{\mathrm{b}}$ \\
\hline Personal distress & $.303^{* \mathrm{a}}$ & $-.278^{\mathrm{b}}$ & $.135^{\mathrm{a}, \mathrm{b}}$ \\
\hline Self-insight & $.044^{\mathrm{a}}$ & $-.589^{* \mathrm{~b}}$ & $.172^{\mathrm{a}}$ \\
\hline${ }^{\mathrm{a}, \mathrm{b}}$ Estimates with different superscripts are significantly different based on t-tests. ${ }^{*} \mathrm{P}<.05 ;{ }^{* *} \mathrm{P}<.01$. & \\
\hline
\end{tabular}


Dinger et al., 2009; Sauer et al., 2003). However, interpersonal vigilance might also help to increase the ability to detect alliance ruptures, as observed with undergraduates who seemed to have benefited from their attachment anxiety to connect with the patients' relational experiences. In sum, attachment anxiety seems to play an important role in the detection of alliance ruptures, and the valence of this role, either negative or positive, appears to depend on the status of other variables.

Furthermore, out of the four components of empathy covered by the second hypothesis, only two displayed a significant effect on ruptures' detection performance: perspective-taking and personal distress. Perspective-taking, a cognitive dimension of empathy referring to the spontaneous tendency to adopt others' point of view (Davis, 1983), had a main negative effect on accurate ruptures detection - the effect being even more important for undergraduates. We surmise that it could have misled participants into using theories and rationalization to hypothesize about the patient's emotional state, reducing awareness of their own emotional experience and thus bringing them away from internal clues revealing aspects of the patient's subjectivity. Personal distress, an affective dimension of empathy referring to self-directed emotional reactions such as anxiety and discomfort felt in stressful relationship environments (Davis, 1983), showed an opposite effect on the detection performance of trainees and undergraduates, the former being negative when compared to the latter, which proved positive. Considering that the highest levels of both attachment anxiety and personal distress were found in trainees, our results provide support to Rubino and colleagues' findings (2000), which suggest that more anxiously attached therapists tend to respond less empathically to patients' concerns than less anxious ones. The positive association of personal distress with rupture detection performance in undergraduates could perhaps result in part from an experiment effect, those experiencing more personal distress paying increased attention to the detection task in order not to disappoint the researchers.

Lastly, our results revealed a negative effect of selfinsight, which refers to the therapists' degree of awareness of their own internal state (Van Wagoner et al., 1991), on trainees' accurate ruptures detection. Moreover, the effect of self-insight on trainees significantly differed from the effect of this variable on both undergraduates and professionals. According to Eubanks-Carter et al. (2015), selfawareness allows therapists to focus on their own immediate experience and is essential to alliance rupture detection. However, trainees have perhaps reacted to the experiment with cautiousness regarding their answers by fear of being mistaken and judged based on their limited clinical experience, which might not be the case for undergraduates and therapists.

The absence of main and interaction effects of personal characteristics on inaccurate rupture detection might suggest that this variable is less pertinent than reports of accurate ruptures to assess detection. In addition, because we chose to include a wide variety of mental health professionals and students, considering therapeutic alliance as transversal (Wampold, 2015), a considerable number of participants had no prior knowledge regarding alliance ruptures, and the brief informational presentation given before the experimental task might not have been sufficient to increase their detection performance. It does not only represent a limit to our results, but also something to keep in mind with mental health academic training failing to provide enough knowledge regarding alliance ruptures and how to deal with them.

Although the entire sample respects the minimum number required to achieve the generalizability of the results according to $\mathrm{G}^{*}$ Power (Faul, Erdfelder, Buchner, \& Lang, 2009), the restricted number of participants among the three groups limits the extent of our results. Also, the observation-based method chosen for this study might help to increase objectivity but might have restricted, by the same token, the degree of emotional investment of the participants as observers, limiting the scope of the conclusions to be drawn regarding personal characteristics involved in detection. Some factors may explain why other dimensions of personal characteristics assessed in this study appeared non-significant with rupture detection. Amongst other things, the self-reported nature of the instruments may have induced validity issues such as social desirability biases and disparities between participants' perceptions of their characteristics and their actual ones. Finally, given the considerably higher amount of confrontation ruptures in the experiment, we were unable to address differences regarding the therapists' ability to detect certain types of ruptures based on their personal characteristics. That knowledge could further lead to the establishment of personalized training supervision for therapists and trainees. Despite these limitations, this study offers some interesting insights into the direction that supervision might take for novice and experienced therapists. Therapists trained to identify some aspects of their own relational dynamics as well as their consequences in the therapeutic alliance could become more vigilant regarding their interventions (Williams, 2008). Along with supervision, theoretical and practical training on alliance ruptures' management should be included in all mental health professional training in order to increase therapists' and other professionals' awareness and help prevent alliance deterioration and patient dropout.

\section{Conclusions}

This study sheds light on the need for early and continuing practical training about ruptures detection in association with therapists' personal characteristics in order to improve the efficiency of psychotherapeutic process. It also opens the underexplored field of alliance rupture detection to the scientific community, with the hope of 
arousing the interest of other researchers into broadening and deepening the knowledge on the subject. This could promote awareness regarding rupture detection on a larger scale, both in the scientific and clinical community.

\section{References}

Ackerman, S. J., \& Hilsenroth, M. J. (2001). A review of therapist characteristics and techniques negatively impacting the therapeutic alliance. Psychotherapy: Theory, Research, Practice, Training, 38, 171-185. doi:10.1037/00333204.38.2.171

Ackerman, S. J., \& Hilsenroth, M. J. (2003). A review of therapist characteristics and techniques positively impacting the therapeutic alliance. Clinical Psychology Review, 1-33. doi:10.1016/S0272-7358(02)00146-0

Black, S., Hardy, G., Turpin, G., \& Parry, G. (2005). Self-reported attachment styles and therapeutic orientation of therapists and their relationship with reported general alliance quality and problems in therapy. Psychology and Psychotherapy: Theory, Research and Practice, 78, 363-377. doi:10.1348/147608305X43784

Chen, R., Atzil-Slonim, D., Bar-Kalifa, E., Hasson-Ohayon, I., \& Refaeli, E. (2018). Therapists' recognition of alliance ruptures as a moderator of change in alliance and symptoms. Psychotherapy Research, 28, 560-570. doi: 10.1080/ 10503307.2016.1227104

Colli, A., Gentile, D., Condino, V., \& Lingiardi, V. (2017). Assessing alliance ruptures and resolutions: Reliability and validity of the Collaborative Interactions Scale-revised version. Psychotherapy Research. doi: 10.1080/ 10503307. 2017.1414331

Colli, A., \& Lingiardi, V. (2009). The Collaborative Interactions Scale: A new transcript-based method for the assessment of therapeutic alliance ruptures and resolutions in psychotherapy. Psychotherapy Research, 19, 718-734. doi:10.1080/ 10503300903121098

Coutinho, J., Ribeiro, E., Hill, C., \& Safran, J. (2011). Therapists' and clients' experiences of alliance ruptures: A qualitative study. Psychotherapy Research, 21, 525-540. doi:10.1080/10503307.2011.587469

Coutinho, J., Ribeiro, E., Sousa, I., \& Safran, J. D. (2014). Comparing two methods of identifying alliance rupture events. Psychotherapy, 51, 434-442. doi:10.1037/a0032171

Davis, M. H. (1980). A multidimensional approach to individual differences in empathy. JSAS Catalog of Selected Document in Psychology, 10, 85.

Davis, M. H. (1983). Measuring individual differences in empathy: Evidence for a multidimensional approach. Journal of Personality and Social Psychology, 44, 113-126.

Degnan, A., Seymour-Hyde, A., Harris, A., \& Berry, K. (2016). The role of therapist attachment in alliance and outcome: A systematic literature review. Clinical Psychology \& Psychotherapy, 23, 47-65. doi:10.1002/cpp.1937

Dinger, U., Strack, M., Sachsse, T., \& Schauenburg, H. (2009). Therapists' attachment, patients' interpersonal problems and alliance development over time in inpatient psychotherapy. Psychotherapy: Theory, Research, Practice, Training, 46, 277-290.

Eames, V., \& Roth, A. (2000). Patient attachment orientation and the early working alliance: A study of patient and therapist reports of alliance quality and ruptures. Psychotherapy Research, 10, 421-434. doi:10.1093/ptr/10.4.421

Eubanks, C. F., Muran, J. C., \& Safran, J. D. (2018). Alliance rupture repair: A meta-analysis. Psychotherapy, 55, 508519. doi:10.1037pst0000185
Eubanks-Carter, C., Muran, J.C., \& Safran, J. D. (2010). Alliance ruptures and resolution. In J. C. Muran \& J. P. Barber (Eds.) The therapeutic alliance: An evidence-based approach to practice and training (pp. 74-94). New York, NY: Guilford Press.

Eubanks, C. F., Muran, J. C., \& Safran, J. D. (2015). Rupture Resolution Rating System (3RS): Manual. Unpublished manuscript, Mount Sinai-Beth Israel Medical Center, New York.

Eubanks-Carter, C., Muran, J. C., \& Safran, J. D. (2015). Alliance-focused training. Psychotherapy, 52, 169. doi: 10.1037/a0037596

Faul, F., Erdfelder, E., Buchner, A., \& Lang, A. G. (2009). Statistical power analyses using $\mathrm{G}^{*}$ Power 3.1: Tests for correlation and regression analyses. Behavior Research Methods, 41, 1149-1160. doi:10.3758/BRM.41.4.1149

Gilet, A. L., Mella, N., Studer, J., Grühn, D., \& Labouvie-Vief, G. (2013). Assessing dispositional empathy in adults: A French validation of the Interpersonal Reactivity Index (IRI). Canadian Journal of Behavioural Science/Revue canadienne des sciences du comportement, 45, 42.

Hill, C. E. (2010). Qualitative studies of negative experiences in psychotherapy. In J. C. Muran \& J. P. Barber (Eds.), The therapeutic alliance: An evidence-based guide to practice (pp. 63-73). New York, NY: Guilford Press.

Horvath, A. O., Del Re, A. C., Flückiger, C., \& Symonds, D. (2011). Alliance in individual psychotherapy. Psychotherapy, 48, 9-16. doi:10.1037/a0022186

Horvath, A. O., \& Greenberg, L. S. (1989). Development and validation of the working alliance inventory. Journal of Counseling Psychology, 36, 223-233.

Johnson, B., Taylor, E., D’Elia, J., Tzanetos, D., Rhodes, R., \& Geller, J. D. (1995). The emotional consequences of therapeutic misunderstandings. Psychotherapy Bulletin, 54-58. doi:10.1037/e544582012-014.

Krause, M., Altimir, C., \& Horvath, A. (2011). Deconstructing the therapeutic alliance: reflections on the underlying dimensions of the concept. Clínica y Salud, 22, 267-283. doi:10.5093/c12011v22n3a7

Krause, M., de la Parra, G., Arsítegui, R., Dagnino, P., Tominic, A., Valdés, N., ... Ben-Dov, P. (2007). The evolution of therapeutic change studied through generic change indicators. Psychotherapy Research, 17, 673-679.

Lafontaine, M. F., \& Lussier, Y. (2003). Structure bidimensionnelle de l'attachement amoureux: Anxiété face à l'abandon et évitement de l'intimité [Bidimensional structure of romantic attachment: Anxiety over abandonment and avoidance of intimacy]. Canadian Journal of Behavioural Science, 25, 71-95.

Lecomte, C., Savard, R., Drouin, M., \& Guillon, V. (2004). Qui sont les psychotherapeutes efficaces? Implications pour la formation en psychologie. Revue québécoise de psychologie, 25 (3), 73-102.

Lussier, Y. (1996). Traduction du Interpersonal Reactivity Index de Davis (1980). Document inédit, Université du Québec à Trois-Rivières, Qc.

Marmar, C. R., \& Gaston, L. (1988). Manual for the California psychotherapy alliance scale - CALPAS. Unpublished manuscript, Department of Psychiatry, University of California, San Francisco, CA.

Marmarosh, C. L., \& Kivlighan, D. M., Jr. (2012). Relationships among client and counselor agreement about the working alliance, session evaluations, and change in client symptoms using response surface analysis. Journal of Counseling Psychology, 59, 352-367. doi : 10.1037/a0028907

Marmarosh, C. L., Kivlighan, D. M., Jr., Bieri, K., LaFauci Schutt, J. M., Barone, C., \& Choi, J. (2014). The insecure psychotherapy base: Using client and therapist attachment 
styles to understand the early alliance. Psychotherapy: Theory, Research, \& Practice, 51, 404-412. doi: 10.1037/ a0031989

Marmarosh, C. L., Schmidt, E., Pembleton, J., Rotbart, E., Muzyk, N., Liner, A., ... Salmen, K. (2015). Novice therapist attachment and perceived ruptures and repairs: A pilot study. Psychotherapy, 52, 140-144. doi:10.1037/a0036129

Mellado, A., Suárez, N., Altimir, C., Martínez, C., Pérez, J., Krause, M., \& Horvath, A., (2017). Disentangling the change-alliance relationship: Observational assessment of the therapeutic alliance during change and stuck episodes. Psychotherapy Research, 27, 595-607. doi: 10.1080/ 10503307.2016.1147657

Mikulincer, M., \& Shaver, P. R. (2016). Attachment in Adulthood, Second Edition: Structure, Dynamics, and Change. New York: The Guilford Press.

Muran, J. C., Safran, J. D., Gorman, B. S., Samstag, L. W., Eubanks-Carter, C., \& Winston, A. (2009). The relationship of early alliance ruptures and their resolution to process and outcome in three time-limited psychotherapies for personality disorders. Psychotherapy, 46, 233-248. doi: 10.1037/ a0016085

Regan, A. M., \& Hill, C. E. (1992). Investigation of what clients and counselors do not say in brief therapy. Journal of Counseling Psychology, 39, 168-174. doi:10.1037/0022-0167. 39.2.168

Rhodes, R., Hill, C., Thompson, B., \& Elliot, R. (1994). Client retrospective recall of resolved and unresolved misunderstanding events. Journal of Counseling Psychology, 41, 473483. doi:10.1037/0022-0167.41.4.473

Rosenberger, E. W., \& Hayes, J. A. (2002). Origins, consequences, and management of countertransference: A case study. Journal of Counseling Psychology, 49, 221-232. doi:10.1037/0022-0167.49.2.221

Rubino, G., Barker, C., Roth, T., \& Fearon, P. (2000). Therapist empathy and depth of interpretation in response to potential alliance ruptures: The role of therapist and patient attachment styles. Psychotherapy Research, 10, 408-420.

Safran, J. D., Crocker, P., McMain, S., \& Murray, P. (1990). The therapeutic alliance rupture as a therapy event for empirical investigation. Psychotherapy, 27, 154-165. doi: 10.1037/ 0033-3204.27.2.154

Safran, J. D., \& Kraus, J. (2014). Alliance ruptures, impasses, and enactments: A relational perspective. Psychotherapy, 51, 381-387. doi:10.1037/a0036815

Safran, J. D., \& Muran, J. C. (1996). The resolution of ruptures in the therapeutic alliance. Journal of Consulting and Clinical Psychology, 64, 447-458. doi:10.1037/0022006X.64.3.447

Safran, J. D., \& Muran, J. C. (2000). Negotiating the therapeutic alliance: A relational treatment guide. New York, NY: Guilford Press.

Safran, J. D., Muran, J. C., \& Eubanks-Carter, C. (2011). Repairing Alliance Ruptures. Psychotherapy, 48, 80-87. doi: $10.1037 / \mathrm{a} 0022140$

Safran, J. D., Muran, J. C., \& Samstag, L. W. (1994). Resolving therapeutic alliance ruptures: A task analytic investigation. In A. O. Horvath, \& L. S. Greenberg (Eds.) The Working alliance: Theory, research, and practice (pp. 225-255). New York: Wiley.

Safran, J. D., Muran, J. C., Samstag, L. W., \& Stevens, C. (2002). Repairing alliance ruptures. In J. C. Norcross (Ed.), Psychotherapy relationships that work. New York, NY: Ox- ford University.

Safran, J. D., Muran, J. C., Samstag, L. W., \& Winston, A. (2005). Evaluating alliance-focussed intervention for potential treatment failures: A feasibility study and descriptive analysis. Psychotherapy: Theory, Research, Practice, Training, 42, 512-531.

Safran, J. D., Muran, J. C., Stevens, C., \& Rothman, M. (2007). A relational approach to supervision: addressing ruptures in the alliance. In Casebook for clinical supervision: a competency-based approach. (pp. 137-157). Washington DC: American Psychological Association.

Samstag, L. W., Muran, J. C., \& Safran, J. D. (2004). Defining and identifying alliance ruptures. In D. Charman (Ed.), Core concepts in brief dynamic psychotherapy (pp. 187-214). Hillsdale, NJ: Erlbaum.

Sauer, E. M., Lopez, F. G., \& Gormley, B. (2003). Respective contributions of therapist and client adult attachment orientations to the development of the early working alliance: A preliminary growth modeling study. Psychotherapy Research, 13, 371-382. doi:10.1093/ptr/kpg027

Simpson, J. A., Rholes, W. S., \& Phillips, D. (1996). Conflict in close relationships: An attachment perspective. Journal of Personality and Social Psychology, 71, 899-914. doi:10.1037/0022-3514.71.5.899

Stevens, C. L., Muran, J. C., Safran, J. D., Gorman, B. S., \& Winston, A. (2007). Levels and patterns of the therapeutic alliance in brief psychotherapy. American Journal of Psychotherapy, 61, 109-129.

Stiles, W. B., Glick, M. J., Osatuke, K., Hardy, G. E., Shapiro, D. A., Agnew-Davies, R., ... Barkham, M. (2004). Patterns of alliance development and the rupture-repair hypothesis: Are productive relationships u-shaped or v-shaped? Journal of Counseling Psychology, 51, 81-92. doi:10.1037/00220167.51 .1 .81

Strauss, J. L., Hayes, A. M., Johnson, S. L., Newman, C. F., Brown, G. K., Barber, J. P., ... Beck, A. T. (2006). Early alliance, alliance ruptures, and symptom change in a nonrandomized trial of cognitive therapy for avoidant and obsessive-compulsive personality disorders. Journal of consulting and clinical psychology, 74, 337-345. doi:10.1037/ 0022-006X.74.2.337

Tabachnick, B. G., \& Fidell, L. S. (2007). Using multivariate statistics. Boston, MA: Allyn \& Bacon/Pearson Education.

Van Wagoner, S. L., Gelso, C. J., Hayes, J. A., \& Diemer, R. A. (1991). Countertransference and the reputedly excellent therapist. Psychotherapy: Theory, Research, Practice, Training, 28, 411-421. doi:10.1037/0033-3204.28.3.411

Wampold, B. E. (2015). How important are the common factors in psychotherapy? An update. World Psychiatry, 14, 270277. doi: $10.1002 /$ wps. 20238

Wei, M., Russell, D. W., Mallinckrodt, B., \& Vogel, D. L. (2007). The experiences in close relationship scale (ECR)Short Form: Reliability, validity, and factor structure. Journal of Personality Assessment, 88, 187-204. doi:10.1080/00223890701268041

Williams, E. N. (2008). A psychotherapy researcher's perspective on therapist self-awareness and self-focused attention after a decade of research. Psychotherapy Research, 18, 139146. doi:10.1080/10503300701691656

Zweig, M. H., \& Campbell, G. (1993). Receiver-operating characteristic (ROC) plots: a fundamental evaluation tool in clinical medicine. Clinical chemistry, 39, 561-577. 